Revista Científica ANAP Brasil

ISSN 1984-3240 - Volume 13, número 29, 2020

\title{
Educação Ambiental em escolas públicas de Mato Grosso
}

Environmental Education in public schools in Mato Grosso

Educación ambiental en escuelas públicas de Mato Grosso

Sandra Gonçalves Ribeiro Kolcenti

Graduada em Biologia, IFMT Campus Confresa, Brasil. Sandrakolcenty@gmail.com

Mônica Strege Médici Professora de Biologia, Seduc/MT, Brasil. stregemonica@hotmail.com

Marcelo Franco Leão Professor Doutor, IFMT, Brasil. marccelo.leao@cfs.ifmt.edu.br 


\title{
Revista Científica ANAP Brasil
}

\author{
ISSN 1984-3240 - Volume 13, número 29, 2020
}

RESUMO

A Educação Ambiental (EA) é um instrumento de transformação na busca por um mundo melhor, mais sustentável e com justiça socioambiental, que promove a formação de pessoas para enfrentar criticamente a exploração desenfreada dos recursos naturais e exercer o papel de agentes transformadores da sociedade por meio de novas práticas. Esse estudo bibliográfico teve por objetivo realizar uma reflexão teórica de como a EA é abordada nas escolas, especialmente nas escolas públicas de Mato Grosso. Esta pesquisa caracteriza-se quanto a abordagem qualitativa, exploratória e descritiva. Constatou-se que no estado, a EA apresenta uma realidade protagonizada por diversas instituições, pesquisadores e entidades não governamentais. Além disso, possui leis, programas, projetos em parcerias, redes, comissões e coletivos educadores, que constitui e formam uma grande comunidade de aprendizagem na busca de fortalecer uma educação capaz de criar condições para compreender as diversas relações que se estabelecem no ambiente. Em 2019, o governador do estado sancionou a Lei de no 10.903 que revoga a Lei 7.888 , de 2003, estabelecendo os processos de aprendizagem voltadas a conservação e melhoria do meio ambiente e qualidade de vida, tanto dentro da escola quanto fora. Com a alteração, o entendimento atual é de que a sensibilização da população é o ponto de partida e que a escola é vista como agente capaz de promover mudanças de hábitos no sentido de prevenir e conservar o meio ambiente.

PALAVRAS-CHAVE: Educação Ambiental. Escola. Meio ambiente.

\section{ABSTRACT}

Environmental Education (EE) is an instrument of transformation that seeks a better, more sustainable world with socio-environmental justice, which promotes the training of people to critically face the unbridled exploitation of natural resources and exercise the role of transforming agents of society through new practices. This bibliographic study aimed to conduct a theoretical reflection on how EE is approached in schools, especially in public schools in Mato Grosso. This research is characterized by its qualitative, exploratory and descriptive approach. It was found that in the state, EE presents a reality led by several institutions, researchers and non-governmental entities. In addition, it has laws, programs, partnership projects, networks, commissions and educative collectives, which constitute and form a large learning community in the search to strengthen an education capable of creating conditions to understand the various relationships that are established in the environment. In 2019, the state governor signed Law No. 10,903, which repeals Law 7,888, of 2003, establishing the learning processes aimed at conservation and improvement of the environment and quality of life, both inside and outside the school. With the change, the current understanding is that public awareness is the starting point and that the school is seen as an agent capable of promoting changes in habits in order to prevent and conserve the environment.

KEYWORDS: Environmental Education. School. Environment.

\section{RESUMEN}

La Educación Ambiental (EA) es un instrumento de transformación que busca un mundo mejor y más sostenible con justicia social y ambiental, que promueve la capacitación de las personas para enfrentar críticamente la explotación desenfrenada de los recursos naturales y ejercer el papel de agentes transformadores de la sociedad a través de nuevas prácticas. Esse estudio bibliográfico tuvo como objetivo realizar una reflexión teórica sobre cómo se aborda la EE en las escuelas, especialmente en las escuelas públicas de Mato Grosso. Esta investigación se caracteriza por su enfoque cualitativo, exploratorio y descriptivo. Se encontró que en el estado, EA presenta una realidad liderada por varias instituciones, investigadores y entidades no gubernamentales. Además, cuenta con leyes, programas, proyectos de asociación, redes, comisiones y colectivos educativos, que constituyen y forman una gran comunidad de aprendizaje en la búsqueda de fortalecer una educación capaz de crear condiciones para comprender las diversas relaciones que se establecen en el entorno. En 2019, el gobernador del estado firmó la Ley $N^{\circ} 10.903$, que deroga la Ley 7.888, de 2003, que establece los procesos de aprendizaje destinados a la conservación y mejora del medio ambiente y la calidad de vida, tanto dentro como fuera de la escuela. Con el cambio, la comprensión actual es que la conciencia pública es el punto de partida y que la escuela es vista como un agente capaz de promover cambios en los hábitos para prevenir y conservar el medio ambiente.

PALABRAS CLAVE: Educación Ambiental. Escuela. Medio ambiente. 


\title{
Revista Científica ANAP Brasil
}

\author{
ISSN 1984-3240 - Volume 13, número 29, 2020
}

\section{INTRODUÇÃO}

A humanidade depende da natureza e dos recursos naturais existentes para sobreviver, assim, as questões ambientais estão cada vez mais sendo influenciadas pelas práticas de vida adotadas pelas pessoas em sociedade. $O$ meio ambiente sofre diariamente transformações que afetam a vida dos seres vivos do planeta. Enfrentamos problemas como: queimadas, poluição do ar por gases tóxicos, poluição água, intoxicação por uso excessivo de agrotóxicos e desmatamento constante na floresta amazônica.

A ampla maioria desses problemas é provocada pela ação do homem, a exemplo das queimadas criminosas na região amazônica. Nesse sentido, percebe-se a necessidade de promover ações que sensibilizem as pessoas para a responsabilidade ambiental. A escola por sua vez, não pode se omitir de desempenhar seu papel de agente de transformação social, que forma pessoas para o exercício de sua cidadania. Assim sendo, é fundamental evidenciar a importância da Educação Ambiental (EA) no processo de sensibilização dos estudantes sobre os cuidados, por meio de ações individuais e coletivas que possam garantir a qualidade ambiental.

É fundamental que o ser humano compreenda, desde cedo, que precisa cuidar conservar e preservar o meio ambiente, visto que o futuro do planeta depende do equilíbrio ambiental, por isso é necessário repensar e fazer o uso racional dos recursos naturais. Assim, o educador precisa instigar o estudante, da forma mais simples possível ao observar o ambiente a sua volta para que o mesmo possa encontrar os elementos necessários no sentido de construir saberes referentes às questões ambientais (MEDEIROS et al., 2011).

Segundo Santos e Gardolinski (2018), é determinante que a EA seja desenvolvida nas escolas para amenizar os problemas que, há anos, vem sendo intensificado ao meio ambiente pelo homem. As crianças representam o futuro da nossa geração em formação e, como estão em fase de desenvolvimento cognitivo, podem ser sensibilizadas, pois os mesmos são sujeitos em formação.

Nesse sentido, entende-se que a escola tem um papel de suma importância no processo de educação, visto que é um espaço social, capaz de formar um cidadão crítico e capaz de agir na sociedade. Para isso, a educação não podendo ser apenas transmissora de conceitos biológicos, sendo necessário um trabalho disciplinar e contínuo para formar cidadãos conscientes, críticos e ativos na sociedade.

Dado a relevância social e a importância de se compreender o papel da escola na EA, esse estudo tem por finalidade realizar um levantamento teórico acerca da EA dentro do ambiente escolar, ressaltando sua importância e contribuição para a formação integral do sujeito para que o mesmo possa agir criticamente e intervir na sociedade. Tendo como enfoque as escolas do estado de Mato Grosso (SEDUC/MT). Assim, a presente revisão foi estruturada e organizada em três partes fundamentais: introdução, desenvolvimento e considerações. O desenvolvimento por sua vez, conta com temas e subtemas elencados para melhor abordagem e compreensão do assunto. 


\section{Revista Científica ANAP Brasil}

ISSN 1984-3240 - Volume 13, número 29, 2020

\section{PROCEDIMENTOS METODOLÓGICOS}

A abordagem metodológica da pesquisa é de natureza qualitativa do tipo "levantamento bibliográfico" proposto por Cervo e Bervian (1996), na qual teve por finalidade realizar um levantamento teórico acerca da EA no âmbito escolar, especialmente nas escolas públicas de Mato Grosso. Lakatos e Marconi (2012) caracterizam a pesquisa bibliográfica como um levantamento de toda a bibliográfica publicada, em forma de livros, revistas, publicações avulsas e imprensa escrita, com o objetivo de transmitir ao pesquisador toda e qualquer informação pertinentes ao tema.

A pesquisa qualitativa não se prende a representatividade numérica, mas, se foca em um aprofundamento da compreensão de um grupo social, de uma organização, entre outras características (GERHARDT; SILVEIRA, 2009). Nas palavras de Denzin e Lincoln (2006, p.17), "a pesquisa qualitativa é uma atividade situada que localiza o observador no mundo" a partir de um conjunto de práticas materiais interpretativas mediante as quais buscamos a compreensão do mundo social.

Os dados foram coletados pelo pesquisador no período que compreende os meses de outubro a dezembro de 2019. A busca foi realizada em periódicos nacionais: Scielo, Periódicos da CAPES e Google acadêmico, utilizando as seguintes palavras-chaves: Educação Ambiental; escola; meio ambiente. Os textos/artigos foram agrupados para análise considerando os subtemas elencados para esse estudo com o intuito de responder aos objetivos específicos.

\section{REFLEXÕES TEÓRICAS SOBRE EDUCAÇÃO AMBIENTAL}

Estamos vivendo uma ampla precariedade acerca do conhecimento sobre a EA, apesar da repercussão desse tema, complexidade e ter múltiplas dimensões envolvidas, todos tem conhecimento da crise ambiental no mundo, mas a maioria não tem consciência dos tipos de ações e procedimentos que podem ser tomados para se evitar. "O homem enxerga os problemas ambientais como se fossem originados independentes das suas práticas sociais" (LOUREIRO, 2005, p. 11).

Mas, para Loureiro (2005) não há consenso sobre o sentido de EA, diversos autores retratam que a EA é um instrumento de transformação social para atingir mudança ambiental e não apenas como ela é compreendida tradicionalmente, um instrumento que busca a mudança cultural e/ou comportamental, em prol de buscar no homem sua autotransformação de forma a atingir a mudanças socioambientais.

Ao longo dos anos diversos autores buscaram contextualizar a EA. No Congresso de Belgrado, ocorrido em 1975, a EA ficou definida como sendo um processo que tem por finalidade formar uma população mundial consciente que visa a preocupação com o ambiente e os problemas inerentes ao mesmo, uma população que tenha conhecimento, competência, estado de espirito, motivação e que busquem a resolução dos problemas atuais de forma individual ou coletiva, evitando que estes se repitam futuramente.

Segundo relatório da UNESCO (1977), a EA é fruto de uma reorientação e articulação das diferentes disciplinas e experiências educativas, que promovem a percepção do meio ambiente, 


\title{
Revista Científica ANAP Brasil
}

\author{
ISSN 1984-3240 - Volume 13, número 29, 2020
}

sendo possível a utilização de ações racionais capazes de responder efetivamente as necessidades sociais.

A agenda 21 é definida como um instrumento de planejamento participativo que visa o desenvolvimento sustentável. No Capítulo 36 da Agenda 21, a EA é definida como o processo que busca;

[...] desenvolver uma população que seja consciente e preocupada com o meio ambiente e com os problemas que Ihes são associados. Uma população que tenha conhecimentos, habilidades, atitudes, motivações e compromissos para trabalhar, individual e coletivamente, na busca de soluções para os problemas existentes e para a prevenção dos novos (MARCATTO, 2002, p. 14).

Segundo a Lei no 9795/99, a EA compreende os processos em que a sociedade constrói valores sociais, conhecimentos, habilidades, atitudes e competências voltadas para a conservação e preservação do meio ambiente, garantindo uma qualidade e vida e sustentabilidade.

O meio ambiente proporciona ao ser humano viver com qualidade de vida ou não, depende da ação que o homem exerce sobre ele. A maioria da população ignora que a manutenção do meio ambiente saudável lhe proporciona uma melhor qualidade de vida. Dessa forma, a EA é um processo que busca a sensibilização do ser humano, e é necessário um esforço continuo e a cooperação não só individual, mas coletiva. É possível esclarecer a população sobre atitudes corretas em relação ao meio ambiente e proporcionar por meios de projetos medidas para amenizar os problemas existentes.

Para Santos et al. (2000, p. 37):

\begin{abstract}
A Educação Ambiental é a prática educacional que ocorre em sintonia com a vida em sociedade, que pode (e deveria) ser inserida sob diversos enfoques: social, econômico, político, cultural, artístico etc., não podendo ser considerada como uma prática estanque, uma vez que abrange diversas áreas. Desta forma também pode ser considerada como uma arte, no sentido de trabalhar com a criatividade no que tange procurar alternativas para envolver os indivíduos num processo de reeducação de valores, percepções e sentidos em relação a forma de ver e viver o mundo.
\end{abstract}

As Diretrizes Curriculares Nacionais para a Educação Ambiental, Art. 2 을 respalda que:

Educação Ambiental é uma dimensão da educação, é atividade intencional da prática social, que deve imprimir ao desenvolvimento individual um caráter social em sua relação com a natureza e com os outros seres humanos, visando potencializar essa atividade humana com a finalidade de torná-la plena de prática social e de ética ambiental (BRASIL, 2012 p. 2).

Essa dimensão educacional é reafirmada por Quintas (2006), pois acredita que a EA proporcione as condições necessárias para que os grupos sociais possam atuar de maneira crítica e consciente na gestão do uso de recursos naturais e na concepção e aplicação de decisões que 


\title{
Revista Científica ANAP Brasil
}

\author{
ISSN 1984-3240 - Volume 13, número 29, 2020
}

não afetem o meio ambiente, seja ele de origem físico-natural ou ainda enquanto construção humana, ou seja, a EA é vista pelo autor como um instrumento de transformação social.

\section{EDUCAÇÃO AMBIENTAL NO COTIDIANO ESCOLAR}

A partir da década de 60, com a publicação do livro "Primavera Silenciosa", há um despertar para a necessidade de preservar o meio ambiente. Percebe-se que é preciso levar o indivíduo a perceber que todos fazem parte de uma mesma comunidade e que as ações humanas afetam os ecossistemas, e que, por isso, é necessário agir com precaução, visando a preservação do meio ambiente, de maneira a mudar a visão do indivíduo com relação ao ambiente em que vive, ou seja, não se restringe a um ambiente fechado, mas envolvendo a família e o coletivo (MEDEIROS, et al., 2011).

Oficialmente a EA iniciou no Brasil em meados dos anos de 1973, por meio do Decreto no 70.030 que se criou a Secretaria Especial do Meio Ambiente. Na qual uma de duas atribuições se constituía em esclarecer e educar o povo brasileiro quanto ao uso adequado dos recursos naturais, visando a conservação do meio ambiente (LIPAI; LAYRARGUES; PEDRO, 2007). Nota-se que na época a preocupação estava direcionada ao gerenciamento de recursos e não a EA emancipatória. Tal abordagem política possui relação com a época em questão, quando iniciavase a discussão acerca da crise ambiental e seus possíveis mecanismos possíveis.

Em 1981, surge a Lei no 6.938 que institui a Política Nacional do Meio Ambiente (PNEA), que salienta a importância dessa dimensão pedagógica no Brasil, destacando a necessidade de promover uma EA a todos os níveis de ensino (LIPAI; LAYRARGUES; PEDRO, 2007). Segundo a legislação mencionada:

A Política Nacional do Meio Ambiente tem por objetivo a preservação, melhoria e recuperação da qualidade ambiental propícia à vida, visando assegurar, no País, condições ao desenvolvimento socioeconômico, aos interesses da segurança nacional e à proteção da dignidade da vida humana, atendidos os seguintes princípios (BRASIL, 1981, Art.2º).

Apesar dos 32 anos de implementação desta lei, ela ainda parece ser uma novidade nas escolas. Contudo, esses foram os primeiros passos conquistados pelo Brasil, e então surgiram muitas políticas voltadas especificamente para EA, que vieram não somente para a EA escolar, mas também como uma tendência socioambiental.

Assim, espera-se que as ações pedagógicas que envolvem EA desenvolvam a sensibilidade, responsabilidade, competência e cidadania ambiental, o que vai além da sala de aula. A educação acontece como parte da ação humana de transformar a natureza em cultura, atribuindo-lhes sentidos, trazendo-a para o campo da compreensão e de experiência humana de estar no mundo e participar da vida de forma sustentável (GAMA, 2017). "Entre conhecimento e ação, ou, ainda mais importante, entre conhecimento e comportamento harmônico com a natureza, existe uma grande distância que precisa ser compreendida para que as mudanças almejadas possam ser alcançadas" (MARCATTO, 2002, p. 4). 


\title{
Revista Científica ANAP Brasil
}

\author{
ISSN 1984-3240 - Volume 13, número 29, 2020
}

Sabe se que a EA surgiu como resposta à demanda social, no intuito de trabalhar o tema desde a educação básica. Em outras palavras, a EA deveria incluir valores, capacidades, conhecimentos, responsabilidades e aspectos que promovam o progresso das relações éticas entre o homem e o meio ambiente como parte integrante do mesmo (MEDEIROS, et al., 2011).

A promulgação da PNEA foi estabelecida pele Lei no 9.795, de 27 de abril 1999, a qual dispõe sobre a introdução da EA no ensino formal, de modo que ela não seja concebida enquanto uma disciplina isolada do currículo, mas permeie todas as áreas do conhecimento, partindo do pressuposto que a dimensão ambiental também engloba os aspectos sociais, econômicos, políticos, culturais e históricos.

A EA objetiva atingir a sociedade, mostrando que todas as pessoas precisam ter acesso a informações que permitam a população participar ativamente na minimização dos problemas ambientais. De acordo com Marcatto (2002), a EA divide-se em educação formal e informal. A educação formal engloba estudantes em geral, da educação infantil até a educação universitária, professores e todos os profissionais que estejam envolvidos com a educação.

O ensino informal, por sua vez, envolve a população de modo geral como, grupos de jovens, de mulheres e muitos outros. A EA é destinada a toda população, porém o foco atual é o ensino infantil e fundamental devido à possibilidade dos estudantes se tornarem futuros agentes dispersores das informações (MARCATTO, 2002).

Há necessidade de um uso equilibrado e mais criterioso dos recursos naturais, para ajustar as relações do homem com o meio ambiente, visando uma sobrevivência mais equilibrada. 0 estreitamento das relações intra e extraescolar, vem ser de grande importância na conservação do ambiente principalmente na fase escolar (SOUZA, 2000). Nesse sentido, indica-se que a EA seja trabalhada pelo lado racional e estruturado juntamente com uma abordagem a sensível visando a construção de valores, a fim de propiciar oportunidade mais significativa que possam ampliar o interesse, a autoconfiança o engajamento e a participação de indivíduos em promover benefícios socioambientais.

Para que haja transformação de percepção do ser humano frente natureza é necessário que os indivíduos passem a efetuar uma ação educativa plena, integral e articulada as outras condições ambientais de vida consolidando ao modelo atual da sociedade e suas relações sociais. A mudança cultural e social de um indivíduo pode contribuir junto as correntes pedagógicas da educação como uma proposta na mudança ambiental, esta junção torna-se necessária devido aos problemas ambientais originados pelo homem, isto é, pelas práticas sociais (LOUREIRO, 2005).

Dentre as diversas abordagens acerca da EA no contexto escolar, tem-se uma adesão às vertentes comportamentalistas e moralistas (formal), que por sua vez acabam somente reproduzindo conhecimento. A educação precisa encontrar meios de viabilizar por meio da análise local reflexões no intuito de construir atitudes adequadas referentes à preservação, e não a importância socioeconômica e cultural do meio, para quem trabalha a $E A$, como é proposto nos Parâmetros Curriculares Nacionais (PCN).

Em seus estudos, Medeiros et al. (2011) ressaltam que a EA, na formação de jovens, pode ser uma efetiva forma de sensibilizar os estudantes para um convívio mais íntimo com a natureza, podendo ser trabalhada com grande frequência nas escolas, por este ser um lugar de formação de futuros cidadãos. Com isso, cabe aos professores estimular os estudantes que sobre a 


\section{Revista Científica ANAP Brasil}

ISSN 1984-3240 - Volume 13, número 29, 2020

importância de adotar medidas que visam preservar a natureza, podendo assim construir um lugar melhor para se habitar, com qualidade de vida e garantido a existência do planeta.

\section{EDUCAÇÃO AMBIENTAL EM ESCOLAS DO ESTADO DE MATO GROSSO}

No estado de Mato Grosso, a educação é regida pela Constituição Estadual de 1989; a Lei Complementar no 049/98, que institui o Sistema Estadual de Educação; a Lei Complementar no 7.040/98, que institui a gestão Democrática nas escolas estaduais; e o Plano Estadual de Educação, Lei no 8806/08, dentre outros instrumentos legais, são de suma importância para construir um currículo que tenha nos direitos humanos seu lócus principal.

Segundo a Secretaria do Estado de Educação de Mato Grosso (SEDUC/MT), a EA apresenta uma realidade protagonizada por diversas instituições, pesquisadores e entidades não governamentais. Além disso, possui leis, programas, projetos em parcerias, redes, comissões e coletivos educadores, que constitui e formam uma grande comunidade de aprendizagem na busca de fortalecer uma educação capaz de criar condições para compreender as diversas relações que se estabelecem no ambiente (MATO GROSSO, 2010).

A Educação Ambiental em sala de aula é uma necessidade social e cultural, porém é bom deixar claro que a mesma não irá resolver todos os problemas ambientais ou salvar o planeta, mas irá criar o respeito e a visão de que devemos cuidar e proteger a natureza para manter as futuras gerações (VIRGENS, 2011, p. 1).

Entre os anos de 2005 e 2006, cerca de 700 professores e 400 estudantes, nos polos do estado, juntamente aos membros da comunidade, participação das Formações Continuadas em EA do Projeto de Educação Ambiental (PrEA) sob a coordenação do Grupo de Educação Ambiental/Superintendência de Ensino e Currículo da SEDUC. A intenção da PrEA era fortalecer os espaços escolares, visando transformar a escola em um lugar de aprendizagem atrativa e inclusiva, a partir de atividades como construção de Projeto Ambiental Escolar e Comunitário (PAEC). Até os anos de 2007, mais de 7000 professores e 249.731 estudantes foram beneficiados indiretamente (GOMES; BORDEST, 2007).

A EA no estado de Mato Grosso tem seu reconhecimento nacionalmente e internacionalmente pelos seus protagonistas, e também por seus projetos e parcerias que marcam o histórico do movimento ecológico. Orientado pela Lei 9.795 de 1999, conhecida como PNEA, e amparada no Programa Nacional de Educação Ambiental (ProNEA), os Estados se organizam em redes e comissões colegiadas para traçarem diretrizes, metas e proposições (GOMES; BORDEST, 2007). O estado de Mato Grosso não se exime de seu compromisso, a EA é abordada por diversas instituições, pesquisadores e entidades não governamentais. Além disso, o estado possui leis, programas, projetos em parcerias, redes, comissões e coletivos educadores que fortalecem a educação popular (GOMES; BORDEST, 2007).

De acordo com dados disponibilizados pelo Instituto Nacional de Educação e Pesquisa Anísio Teixeira (Inep) e da Coordenação Geral de Educação Ambiental (Cegea/MEC), o número de escolas que afirmam desenvolver práticas de EA é significativa, sendo ações práticas 


\title{
Revista Científica ANAP Brasil
}

\author{
ISSN 1984-3240 - Volume 13, número 29, 2020
}

desenvolvidas por meio de projetos, disciplinas especificas e/ou por inclusão do tema nas disciplinas. Os dados ainda revelam o aumento no número de matrículas em escolas de Ensino Fundamental que oferecem a EA, entre os anos de 2001-2004, destacando-se a região Centrooeste, especificamente o estado de Mato Grosso (MATO GROSSO, 2010).

Em 2019, foi sancionada pelo governador de Mato Grosso, Mauro Mendes, a Política Estadual de Educação Ambiental (PEEA), durante as comemorações da XV semana do Meio Ambiente. A Lei no 10.903 , de 7 de junho de 2019, estabelece os processos de aprendizagem voltadas a conservação e melhoria do meio ambiente e qualidade de vida, tanto dentro da escola quanto fora. Essa lei teve uma boa repercussão e foi amplamente debatida entre diversas instituições e com a participação de 91 municípios e mais de 1500 pessoas, além do acompanhamento pelo Ministério Público Estadual.

A EA é um direito de todos, a inclusão social e a responsabilidade socioambiental necessitam ser buscadas e desenvolvidas em unidades escolares e fora das unidades. $\mathrm{O}$ atual governador de Mato Grosso afirma que a educação é a maior fonte de transformação, pois cria oportunidade e uma nova consciência e uma nova geração. Mauro Mendes acredita que no meio ambiente não funcione diferente, afirma que é possível contribuir com as ações de preservação e, acima de tudo, com a consciência e uma nova doutrina que vem surgindo para essa e as novas gerações. Segundo a Lei no 10.903 de 2019, entende-se por EA

[...] os processos contínuos e permanentes de aprendizagem, em todos os níveis e modalidades de ensino, em caráter formal e não formal, por meio dos quais os indivíduos e a coletividade constroem e compartilham valores sociais, espirituais, étnicos, culturais, conhecimentos e habilidades, atitudes e competências, voltadas à sensibilização, prevenção, conservação, preservação, recuperação e melhoria do meio ambiente e da qualidade de vida e sua sustentabilidade.

Todos os municípios e regiões do estado de Mato Grosso serão incentivados e apoiados pela criação, além do funcionamento de instâncias, conselhos, câmaras técnicas e fundos municipais destinados a apoiar ações de EA, comissões ou outras formas de articulação das instituições e pessoas que atuam com EA.

Segundo a Lei no 10.903, de 2019:

Art. 20 A Educação Ambiental será desenvolvida como uma prática educativa integrada, contínua e permanente, em todos os níveis e modalidades do ensino escolarizado, considerando a pluralidade e a diversidade individual cultural e promovendo a partilha de saberes.

§ 1ํ A Educação Ambiental deverá ser implantada no Projeto Político Pedagógico (PPP) escolar, de forma transversal e interdisciplinar, integrada às demais disciplinas e não como disciplina específica no currículo de ensino.

$\S$ 2o Nos cursos de graduação, pós-graduação e extensão é facultativa a criação de disciplina específica de Educação Ambiental.

§ 3은 Nas áreas voltadas ao aspecto metodológico da Educação Ambiental é obrigatória a criação de disciplina específica de Educação Ambiental. 


\title{
Revista Científica ANAP Brasil
}

\author{
ISSN 1984-3240 - Volume 13, número 29, 2020
}

$\S 4$ 은 Nos cursos de formação e educação profissional em todos os níveis, deve ser incorporado conteúdo que trate da ética e da percepção ambiental das atividades profissionais a serem desenvolvidas.

$\S 5$ Nos cursos de formação inicial e continuada dos servidores públicos municipais e estaduais deve-se incorporar a disciplina de ética e de percepção ambiental.

Art. 21 A dimensão ambiental deve constar dos currículos de formação inicial e continuada de profissionais da educação, em todos os níveis, modalidades e disciplinas. Parágrafo único Todos os profissionais da educação devem participar de cursos de formação e atualização em Educação Ambiental, oferecidos pelas instituições em que trabalham.

Art. 22 As Secretarias de Estado e Municipais de Educação e de Meio Ambiente, em parceria, deverão:

I - Promover cursos e programas de formação inicial e continuada para a comunidade escolar e fora dos espaços escolarizados;

II - Promover sistematicamente a informação ambiental, por meio de todos os veículos de comunicação, objetivando contribuir para a formação de uma consciência crítica, ética e proativa, em prol da sustentabilidade socioambiental.

Além disso, o documento oficial do estado indica que os profissionais da educação em atividade deveriam participar, em sua área de atuação, de cursos de formação continuada, com o propósito de atender adequadamente ao cumprimento dos princípios e objetivos da PEEA.

Como o papel da EA é formar cidadãos críticos e preocupados com o meio ambiente, é importante que essas ações sejam praticadas nas escolas, desde o ensino infantil ao ensino médio, proporcionando um processo de "alfabetização ecológica" nos estudantes. Para abordar a EA nas escolas o professor pode desenvolver diferentes metodologias de ensino, tais como de investigação e experimentação, que busque obter a atenção e a participação de todos os estudantes, promovendo assim, a EA por meio da reflexão do estudante.

Cabe retomar que a Lei 9.795/99 já preconizava que a EA necessita estar sempre presente no processo educativo, de forma articulada e em todos os níveis e modalidades da educação, respeitando as diretrizes nacionais. Além disso, a lei valoriza a abordagem articulada das questões ambientais locais, regionais e nacionais, além de incentivar a busca por alternativas curriculares e metodológicas na capacitação da área ambiental e as iniciativas e experiências locais e regionais, incluindo uma produção de material educativo (BRASIL, 1999).

$O$ processo de EA na escola envolve um trabalho multiprofissional entre toda a comunidade escolar estudantes, professores, equipe administrativa, apoio e se estende também aos pais. É importante desenvolver por meio de projetos mudanças de atitudes que buscam por construção de valores a contextualização e o reconhecimento do espaço em que vivemos. Sendo assim, a EA necessita caminhar de encontro ao desenvolvimento de habilidades e criticidade em torno das atividades voltadas o meio ambiente, bem como aos princípios sociais e ambientais da coletividade.

Desse modo, é possível afirmar que a escola é o local ideal para desenvolver aprendizagens voltadas a formação de atitudes positivas voltadas ao meio ambiente, assim como relatado por Reigota (1999): 


\section{Revista Científica ANAP Brasil}

ISSN 1984-3240 - Volume 13, número 29, 2020

A escola é um espaço privilegiado de informação, construção e produção de conhecimentos, desenvolvimento da criatividade e possibilidades de aprendizagens diversas, onde os professores devem trabalhar na perspectiva de visões cotidianas, exercendo um papel muito importante no processo de construção de conhecimentos dos alunos, na modificação dos valores e condutas ambientais, de forma contextualizada, crítica e responsável (REIGOTA, 1999, p. 69).

Em outras palavras, a escola se constitui como um espaço que o estudante passa por processo de formação e construção de valores e socialização, e com isso passa a adotar um comportamento ambientalmente correto e passa a vivenciá-lo na prática, no cotidiano da vida escolar, e para além da escola contribuindo para a formação de cidadãos responsáveis.

Os autores citados nesse estudo, ressaltam em seus estudos a importância que a EA tem para garantir uma qualidade de vida. Visto que, por meio de uma sensibilização é possível alcançar mudanças no estilo de vida que busquem alternativas para resolução de problemas atualmente identificados - queimadas, efeito estufa, aquecimento global, desmatamento, entre outros bem como a prevenção de problemas futuros.

Nesse sentido, é possível acreditar que a EA possa contribuir de forma significativa para renovar o processo educativo, trazendo a permanente avaliação crítica e adequação a realidade local por meio do envolvimento de todos os sujeitos inseridos no contexto escolar em ações concretas de transformação.

\section{CONSIDERAÇÕES FINAIS}

A escola é um excelente ambiente para a formação de cidadania ambiental, atuando no cotidiano escolar formal e não formal, com o objetivo de solucionar os problemas existentes, de modo a articular a escola para os conhecimentos locais, regionais e globais. Além disso, o espaço escolar é concebido por estabelecer trocas e informações, bem como estimular os estudantes a terem ideias e posturas de cidadãos conscientes de suas responsabilidades e, fundamentalmente por ser partes de um todo e, desse modo, se reconhecendo como integrantes do meio ambiente.

A educação é uma ferramenta fundamental para a intervenção no mundo, ao que tange a elaboração de novos conceitos seguida de mudanças de hábitos e/ou estilos de vida, é ainda, um fator crucial na construção do conhecimento e no desenvolvimento intelectual passado de geração a geração, em sua essência, estimula o senso crítico e desperta o interesse do estudante. A EA nas escolas é o caminho determinante para a construção de uma sociedade ciente do seu papel em relação ao meio ambiente em que vive. Quando abordada de forma contextualizada e com problemáticas acerca da realidade, permite ao estudante se posicionar quanto às polêmicas da atualidade, bem como construir uma sociedade justa, sustentada nos valores da liberdade, igualdade, solidariedade, democracia, justiça social, responsabilidade, sustentabilidade e educação como direito de todos e todas. 


\title{
Revista Científica ANAP Brasil
}

\author{
ISSN 1984-3240 - Volume 13, número 29, 2020
}

Portanto, para ocorrer as mudanças quanto às questões ambientais, se faz necessário um comprometimento de toda a comunidade escolar, na continuidade e manutenção de projeto benéficos ao equilíbrio ambiental. O estado de Mato Grosso possui diversas instituições, pesquisadores e entidades não governamentais. Além disso, possui leis, programas, projetos em parcerias, redes, comissões e coletivos educadores que formam uma grande comunidade de aprendizagem que tem por objetivo a educação permanente e sensibilização em torno das questões voltadas ao meio ambiente. A EA não escolarizada é abordada pelo estado por meio de comunicação de massa, com informações relacionadas ao meio ambiente e qualidade de vida, com a veiculação de programas e campanhas educativas.

\section{AGRADECIMENTO}

Ao IFMT pala formação recebida, pelo apoio e viabilidade para que o estudo ocorresse e resultasse na presente publicação.

\section{REFERÊNCIAS BIBLIOGRÁFICAS}

BRASIL. Lei no 10.903 de 07 de junho de 2019. Dispõe sobre a Política Estadual de Educação Ambiental e revoga a Lei no 7.888, de 09 de janeiro de 2003. Diário Oficial [do] Estado do Mato Grosso, 2019. Disponível em: < http://www.al.mt.gov.br/storage/webdisco/leis/lei10903-2019.pdf> Acesso em 10 de fev 2020.

BRASIL. Lei n. ㅇ 8.806, de 10 de janeiro de 2008. Dispõe sobre o Plano Estadual de Educação e dá outras providências. Diário Oficial [do] Estado do Mato Grosso, 2008. Disponível em: <

http://www.al.mt.gov.br/storage/webdisco/leis/lei-08806-2008.pdf> Acesso em: 10 de fev de 2020.

BRASIL. Lei no 7.040 de 1 de outubro de 1998. Regulamenta os dispositivos do artigo 14 Lei federal no 9.394, de 20 de dezembro de 1996, bem como inciso VI do artigo 206 da Constituição Federal, que estabelecem gestão democrática do Ensino Público Estadual, adotando o sistema seletivo para escolha dos dirigentes dos estabelecimentos de ensino e a criação dos Conselhos Deliberativos da Comunidade Escolar nas Unidades de Ensino, v.14. Disponível em: <http://site.seduc.mt.gov.br/cdce/Lei_7048-98.pdf> Acesso em 10 de fev de 2020.

BRASIL. Lei no 6.938 de agosto de 1981. Dispõe sobre a Política Nacional do Meio Ambiente, seus fins e mecanismos de formulação e aplicação, e dá outras providências, 1981. Disponível em: <

http://www.planalto.gov.br/ccivil_03/LEIS/L6938.htm> Acesso em 4 de dez de 2019.

BRASIL. Lei no 9795 de abril de 1999. Dispõe sobre a educação ambiental, institui a política nacional de educação ambiental e dá outras providências, 1999. Disponível em: < http://www.planalto.gov.br/ccivil_03/leis/l9795.htm> Acesso em 04 de dez de 2019.

BRASIL. Resolução no $\mathbf{2}$ de 15 de junho de 2012, estabelece as Diretrizes Curriculares Nacionais para a Educação Ambiental, 2012. Disponível em: < http://portal.mec.gov.br/dmdocuments/rcp002_12.pdf> Acesso em 4 de dez de 2019.

CERVO, A. L.; BERVIAN, P. A. Metodologia científica. São Paulo: Makron. 1996.

Disponivel em: em: $\quad<$ http://www.scielo.br/scielo.php?script=sci_nlinks\&ref=000074\&pid=S01002945200900040002100006\&lng=pt> Acesso em 19 de dez de 2019.

DENZIN, N. K.; LINCOLN, Y. S.; GIARDINA, M. D. Disciplining qualitative research. International journal of qualitative studies in education, v. 19, n. 6, p. 769-782, 2006. Disponível em: < https://www.tandfonline.com/doi/abs/10.1080/09518390600975990> Acesso em 20 de dez de 2019. 


\title{
Revista Científica ANAP Brasil
}

\author{
ISSN 1984-3240 - Volume 13, número 29, 2020
}

GAMA, A. A. Educação Ambiental: Abordagens e Perspectivas. Revista Científica Multidisciplinar Núcleo do Conhecimento. Edição 07. Ano 02, Vol. 03. pp 52-60, outubro de 2017.

GERHARDT, T.E.; SILVEIRA, D.T. Métodos de pesquisa. Plageder, 2009. Disponível em: https://books.google.com.br/books?hl=ptBR\&lr=\&id=dRuzRyElzmkC\&oi=fnd\&pg=PA9\&dq=GERHARDT,+T.E.\%3B+SIL VEIRA,+D.T.+M\%C3\%A9todos+de+pesquisa.+Plageder,+2009\&ots=92W8010oNI\&sig=NxA5ApjUMPBbjWQP7gbiovrh Xu8. Acesso em 20 de dez de 2019.

GOMES, G.R.N.S; BORDEST, S.M.L. Construção da Educação Ambiental em Mato Grosso. In: IV EPEA- Encontro de Pesquisa em Educação Ambiental, 2007, Rio Claro. Questões Epistemológicas Contemporâneas: o debate modernidade e pós modernidade. Rio Claro: UNESP, 2007. p.1-11. Disponível em: < http://www.epea.tmp.br/epea2007_anais/pdfs/plenary/TR06.pdf> Acesso em: 20 de dez de 2019.

LAKATOS, M.A. MARCONI, M.A. Metodologia do trabalho científico: procedimentos básicos, pesquisa bibliográfica, projeto e relatório, publicações e trabalhos científicos. São Paulo: Atlas, 2012. Disponível em: $<\quad$ https://forumdeconcursos.com/wp-content/uploads/wpforo/default_attachments/1553321464Metodologia-do-trabalho-cientficoEva-M-Lakatos-e-Marina-de-A-Marconi.pdf>02 de jan de 2020

LOUREIRO, C. F. B. Teoria Crítica. In: FERRARO-JUNIOR, L. A. Encontros e Caminhos: formação de educadores ambientais e coletivos educadores. p. 323-332; Brasília: Ministério do Meio Ambiente, Diretoria de Educação Ambiental, 2005. Disponível em: < https://www.mma.gov.br/estruturas/educamb/_arquivos/encontros.pdf> Acesso em 10 de jan de 2020

LIPAI, E.M.; LAYRARGUES, P.P.; PEDRO, V.V. Educação ambiental na escola: tá na lei.... Conceitos e práticas em educação ambiental na escola, 2007. 243p. Disponível em: < http://www.inesul.edu.br/site/documentos/publicacao3.pdf\#page=24> Acesso em 10 de jan de 2020.

MATO GROSSO, Secretaria de Estado de Educação - SEDUC. Política de Educação Ambiental (PEA-SEDUC), Cuiabá: Central de Texto, 2010. Disponível em:

http://www2.seduc.mt.gov.br/documents/9418783/9589638/LIVRO+ORIENTACOES+CURICULARES+DAS+DIVERSID ADES+EDUCACIONAIS+com+ficha+catalografica-t6SXF86A.pdf/08fde3af-308c-5105-712c-f14918b65a8e. Acesso em 10 de dez de 2019.

MARCATTO, M. Educação ambiental: Conceito e princípios. 1.ed. Belo Horizonte MG: Gráfica e Editora Sigma Ltda, 2002. 64 p. Disponível em: < http://jbb.ibict.br/handle/1/494> Acesso em 10 de jan de 2020.

MEDEIROS, A. B. et al. A Importância da educação ambiental na escola nas series iniciais. Revista Faculdade Montes Belos, v.4, n. 1, set. 2011. Disponível em: <

http://www.terrabrasilis.org.br/ecotecadigital/index.php?option=com_abook\&view=book\&cat id=4:educacaoambiental\&id=1462:a-importancia-da-educacao-ambiental-na-escola-nasseries-iniciais\&ltemid=54> Acesso em 10 de jan de 2020 .

QUINTAS, M.A. Organização e gestão hoteleira. Alcabideche: Oteltur, 2006.

REIGOTA, M. Ecologistas. Santa Cruz do Sul: Edunisc, 1999.

SANTOS, S.P.; GARDOLINSK, M.T. A importância da Educação Ambiental nas escolas para a construção de uma sociedade sustentável. Pós-graduação do curso de sustentabilidade e políticas públicas do grupo Uninter, 2018. Disponível em: <http://www2.al.rs.gov.br/biblioteca/LinkClick.aspx?fileticket=1VmNggPU170\%3D\&tabid=5 639> Acesso em 10 de dez de 2019.

SANTOS, J.G. et al. Educação Ambiental, cidadania e sustentabilidade: Um estudo com alunos do ensino fundamental, 2000. Disponível em: < http://www.revistaea.org/pf.php?idartigo=1125> Acesso em 4 de dez de 2019. SOUZA, A. K. A relação escolar-comunidade e a conservação ambiental. 2000. $89 \mathrm{fl}$. Monografia (Especialização em Educação Ambiental), Universidade Federal da Paraíba, Joao Pessoa, Paraíba. Disponível em: <http://www.editorarealize.com.br/revistas/setepe/trabalhos/Modalidade_1datahora_30_09_2014_18_07_41_idi nscrito_329_701a454e2f7a5db74f7004ea3552ea4b.pdf> Acesso em 10 de jan de 2020.

UNESCO - Organização das Nações Unidas para a Educação, Ciência e Cultura - PNUMA - Programa das Nações Unidas para o Meio Ambiente. A Carta de Belgrado: uma estrutura global para a educação ambiental. Belgrado: 


\title{
Revista Científica ANAP Brasil
}

\author{
ISSN 1984-3240 - Volume 13, número 29, 2020
}

UNESCO, 1975. Disponível em< http://www.fzb.rs.gov.br/upload/20130508155641carta_de_belgrado.pdf> Acesso em 04 de dez de 2019.

UNESCO - Organização das Nações Unidas para a Educação, Ciência e Cultura - PNUMA - Programa das Nações Unidas para o Meio Ambiente. Declaração da Conferência Intergovernamental sobre Educação Ambiental. Tbilisi: UNESCO, 1977. Disponível em < http://www.meioambiente.pr.gov.br/arquivos/File/coea/Tbilisi.pdf> Acesso em 04 de dez de 2019.

VIRGENS, R.A. A educação ambiental no ambiente escolar. 1 ed. Brasília, 2011. Disponível em: < http://bdm.unb.br/handle/10483/1753> Acesso em 05 de jan. de 2020. 